\title{
Grain Breakup During Elevated Temperature Deformation of an HCP Metal
}

\author{
PETER D. HONNIBALL, MICHAEL PREUSS, DAVID RUGG, \\ and JOÃO QUINTA DA FONSECA
}

\begin{abstract}
A combination of mechanical testing, EBSD and crystal plasticity finite element modeling were used to investigate the influence of temperature on the fragmentation of grains in a zirconium alloy. The results demonstrate that grains of Zircaloy- 4 fragment more as the temperature rises. This trend can be explained by an increasing difference between the CRSS values for $\langle c+a\rangle$ slip and $\langle a\rangle$ slip as temperature rises. This change in relative slip activities with temperature is supported by experimental observations of macroscopic anisotropy and in-grain misorientation axes calculated from EBSD data, as well as plasticity modeling. By tracking the microstructural evolution during deformation, it is shown that the two major texture components fragment to different degrees under the action of prismatic slip. Grains in the $\langle 11 \overline{2} 0\rangle$ fiber are significantly more stable than those in the $\langle 10 \overline{1} 0\rangle$ fiber, which break up. Grains of the latter fiber fragment heterogeneously as portions of the grain rotate in opposite directions, and some do not rotate at all.
\end{abstract}

DOI: $10.1007 / \mathrm{s} 11661-015-2812-9$

(C) The Author(s) 2015. This article is published with open access at Springerlink.com

\section{INTRODUCTION}

ZIRCONIUM alloys are used in structural components of nuclear reactors, where they are subjected to extreme environments. These components degrade by oxidation, ${ }^{[1]}$ hydride embrittlement, ${ }^{[2]}$ and irradiationenhanced shape change. ${ }^{[3,4]}$ These degradation mechanisms are influenced by a number of material characteristics, which include texture, ${ }^{[4-6]}$ microstructure, ${ }^{[4,5,7]}$ dislocation density, ${ }^{[4]}$ and residual stresses, ${ }^{[4]}$ which are defined during processing. This means that the thermomechanical processing of zirconium components has a significant impact on component's lifetime and reactor efficiency. Currently, achieving the desired microstructure and texture involves using convoluted thermomechanical processing routes, developed empirically. Optimization of material properties and processing parameters requires the development of models that can simulate the microstructural evolution taking place during thermomechanical processing. This requires a deeper understanding of the governing underlying deformation and recrystallization mechanisms.

The recrystallization behaviors of zirconium and titanium have been the subject of a number of

PETER D. HONNIBALL, Metallurgist, formerly with the Materials Science Centre, School of Materials, The University of Manchester, Manchester M13 9PL, U.K., is now with Rolls-Royce PLC, Derby DE24 8BJ, U.K. MICHAEL PREUSS, Professor of Metallurgy, and JOÃO QUINTA DA FONSECA, Senior Lecturer, are with the Materials Science Centre, School of Materials, The University of Manchester. Contact e-mail: joao.fonseca@manchester.ac.uk DAVID RUGG, Materials Fellow, is with Rolls-Royce PLC.

Manuscript submitted July 3, 2014.

Article published online February 27, 2015 studies. ${ }^{[8-13]}$ In the work of Gerspach et al..${ }^{[1]}$ it was shown that the fragmentation of grains has an influence upon the primary recrystallization texture following moderate strain deformation $(\sim 40 \mathrm{pct}) \cdot{ }^{[11]}$ In these cases, oriented nucleation of new grains occurs at fragmented regions of the prior grains. The orientations of the nuclei dominate the texture throughout primary recrystallization. The texture's development in the latter stages of recrystallization and the overall recrystallization process is dominated by the favorable growth of specific grain orientations. ${ }^{[3,8-10,14,15]}$ The frequency of these specific grains following primary recrystallization will influence the texture that develops in secondary recrystallization. ${ }^{[8]}$ Thus, the deformed state of the grains will influence the final recrystallization texture via its influence upon the processes taking place during primary recrystallization. Since grain fragmentation plays a key role during recrystallization, it is important to understand how it occurs and how it is affected by the operating deformation mechanisms.

The aim of this study was to investigate the mechanism of grain fragmentation. We used EBSD to quantify grain breakup by measuring grain average misorientation (GAM) at different stages of deformation and at different temperatures, and to follow grain fragmentation during deformation at $773 \mathrm{~K}$ $\left(500{ }^{\circ} \mathrm{C}\right)$. These results were interpreted subsequently using crystal plasticity finite element modeling (CPFEM).

The structure of the paper is as follows: the initial material state is described in Section II. In Sections III and IV, we discuss the influence of temperature upon the mechanical behavior, microstructural and texture evolutions. In Section IV-C, the influence of the dominant prismatic $\langle\mathrm{a}\rangle$ slip upon the fragmentation of the two main texture components is explored followed by a 
discussion of the influences of temperature and loading direction upon the GAM. The observed experimental trends are interpreted by the use of CPFEM in Section V. Finally, the findings are collated and discussed in Section VI.

\section{MATERIAL}

The material used in this study is Zircaloy-4 plate supplied by Rolls-Royce plc in rolled and recrystallized forms with a typical split basal texture (Figure 1). The properties of Zircaloy-4 including the composition and melting temperature can be found in Reference 16 .

The microstructure is composed of single-phase equiaxed grains of alpha $\mathrm{Zr}$ (HCP) (Figure 1(a)). The texture is made up of a main $\langle 1120\rangle / / \mathrm{RD}$ fiber. This fiber contains a pronounced texture component $\{10 \overline{1} 3\}\langle 11 \overline{2} 0\rangle$ which lies at $\varphi_{1}=0 \mathrm{deg}, \Phi=20 \mathrm{deg}$ to $40 \mathrm{deg}, \varphi_{2}=30 \mathrm{deg}$. This fiber gives rise to maxima along RD in the $(11 \overline{2} 0)$ pole figure (Figure 1(b)). Using the inverse pole figure color scheme given in Figures 5 and $7,\langle 11 \overline{2} 0\rangle / / \mathrm{RD}$ grains are green. For the majority of grains, the (0002) poles are orientated at $20 \mathrm{deg}$ to 30 deg from the ND toward the TD. The ODF shows that there is a spread across $\varphi_{2}$ about the main fiber. As a result, a number of grains also belong to a less distinct fiber $\langle 10 \overline{1} 0\rangle / / \mathrm{RD}$. These can be seen as blue grains in the inverse pole figure color scheme and show up as the regions of maximum (1010) pole intensity about the RD.

\section{MECHANICAL BEHAVIOR}

The material was tested in uniaxial compression. Specimens were deformed along the RD and the ND at $298 \mathrm{~K}, 573 \mathrm{~K}$, and $773 \mathrm{~K}\left(25^{\circ} \mathrm{C}, 300{ }^{\circ} \mathrm{C}\right.$, and $\left.500{ }^{\circ} \mathrm{C}\right)$ up to the maximum strains of 0.07 and 0.6. The samples were cuboidal with dimensions of $9 \times 9 \times 15 \mathrm{~mm}$ (RD compression) and $9 \times 9 \times 10 \mathrm{~mm}$ (ND compression). The final dimensions of the samples strained to 0.07 were measured to determine the Lankford coefficient, defined as the ratio of the two transverse strains, and a useful measure of deformation anisotropy. For the samples compressed along the RD, the Lankford coefficient is given by $\varepsilon_{\mathrm{TD}} / \varepsilon_{\mathrm{ND}}$, whereas for the samples compressed along the ND, it is given by $\varepsilon_{\mathrm{TD}} / \varepsilon_{\mathrm{RD}}$.

An Instron $5885 \mathrm{H}$ loading rig with a $250 \mathrm{kN}$ load cell and an environmental chamber was used for the compression experiments at room and elevated temperatures. The initial strain rate in all of the compression experiments was $10^{-4} \mathrm{~s}^{-1}$.

The stress-strain curves obtained during mechanical loading are shown in Figure 2. Both the yield stress and the hardening behavior of Zircaloy- 4 are temperature sensitive and dependent upon the loading direction. The hardening behavior is noticeably different for the RD and the ND cases. The flow curves measured for RD compression at $298 \mathrm{~K}$ and $573 \mathrm{~K}\left(25^{\circ} \mathrm{C}\right.$ and $\left.300{ }^{\circ} \mathrm{C}\right)$ exhibit an inflection between 0.1 and 0.25 strain, indicating an increase in work-hardening rate. No such inflection exists for RD compression at $773 \mathrm{~K}\left(500{ }^{\circ} \mathrm{C}\right)$ or compression along the ND at any temperature. This inflection has also been seen previously during the

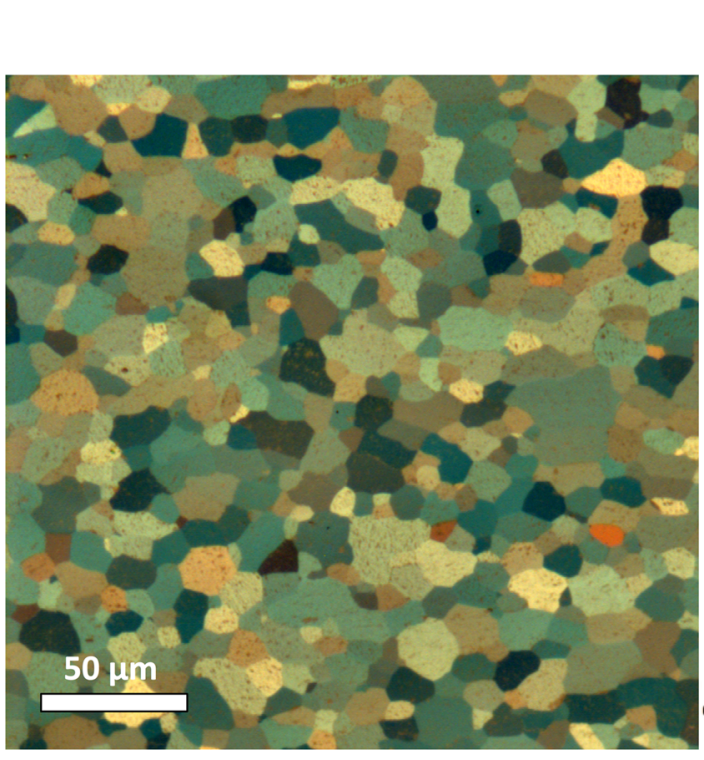

(a)

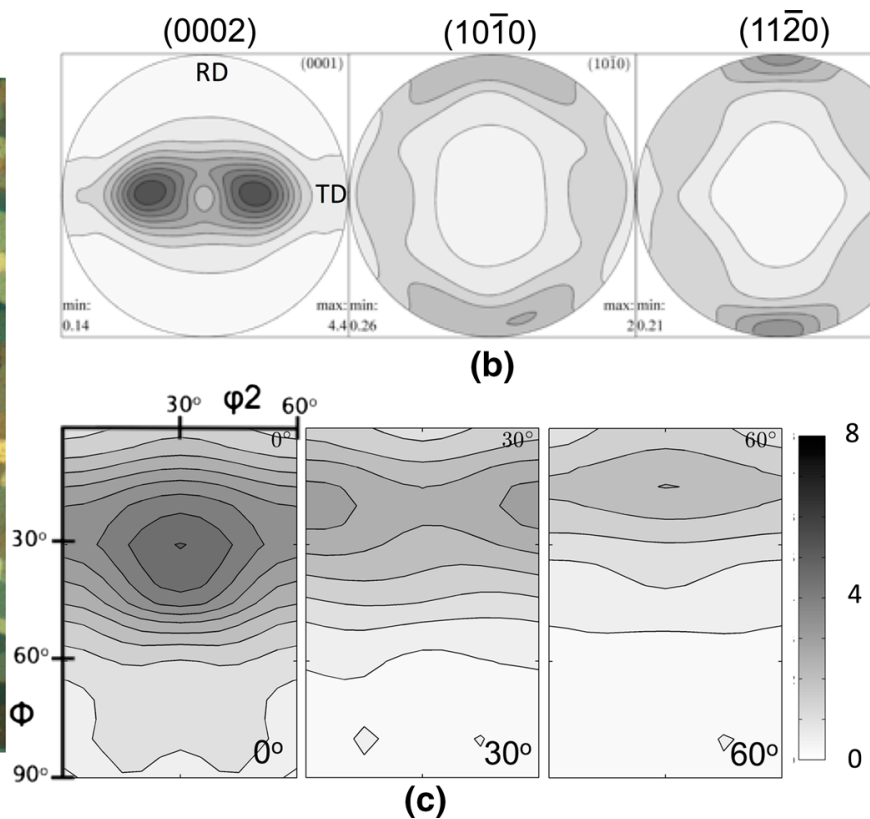

Fig. 1-Initial microstructure (a) and texture in the form of pole figures $(b)$ and $\varphi_{1}$ sections $(c)$. 


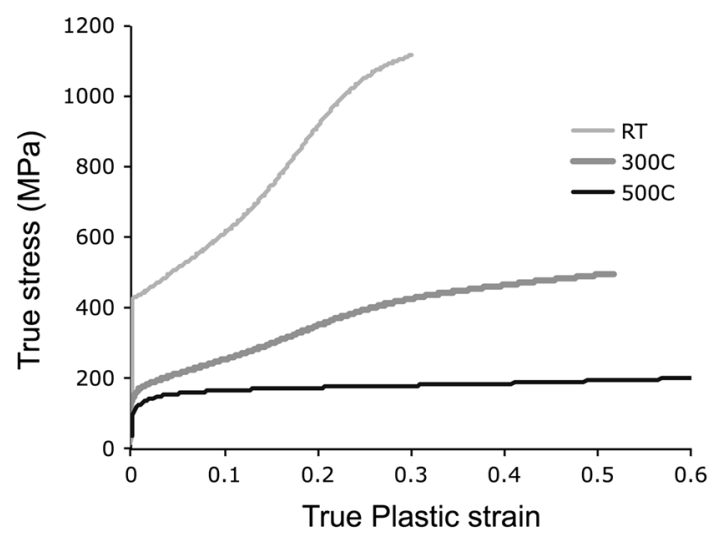

(a)

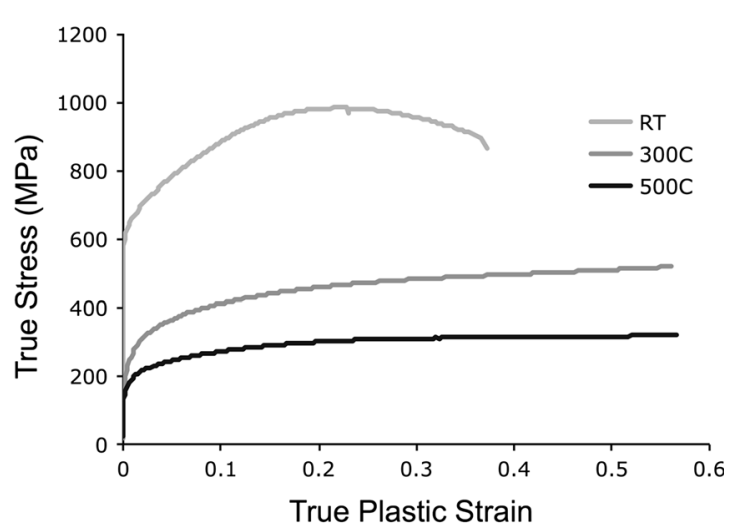

(b)

Fig. 2-True stress vs true plastic strain curves for uniaxial compression at three temperatures along (a) the RD and (b) the ND.

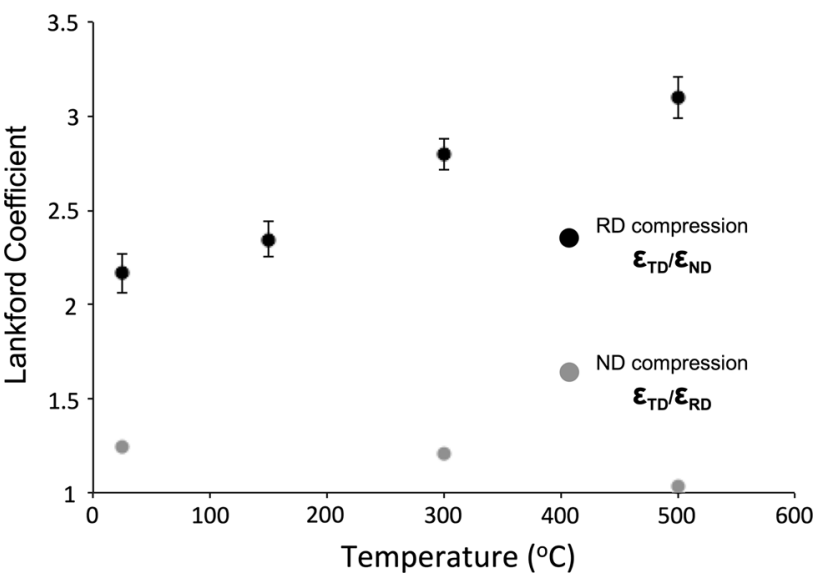

Fig. 3-The variation of Lankford coefficient (after 0.07 strain) with temperature. Lankford coefficients measured after RD compression are calculated from the ratio of the following transverse strains $\varepsilon_{\mathrm{TD}} /$ $\varepsilon_{\mathrm{ND}}$. For ND compression, $\varepsilon_{\mathrm{TD}} / \varepsilon_{\mathrm{RD}}$ is used.

in-plane compression of high-purity $\mathrm{Zr}$ and is indicative of twinning. ${ }^{17,18]}$ At small strains $(<0.1)$, the flow stresses during ND compression are higher than those during RD compression. This is a direct consequence of the texture of the material which makes the easier prismatic slip much more likely for compression along RD than along ND.

The Lankford coefficients calculated from the samples strained to 0.07 are shown in Figure 3. In RD compression, the ratio of the transverse strains is 2.2 , that is, the strain along TD is 2.2 times that along ND. This ratio increases with increasing temperature, reaching 3.1 at $773 \mathrm{~K}\left(500{ }^{\circ} \mathrm{C}\right)$. This suggests that accommodating deformation along the ND becomes relatively more difficult as the temperature increases. During ND compression, the deformation is more isotropic, and the effect of temperature is smaller. However, as the temperature rises, relatively more strain is accommodated along the RD than that along the Transverse Direction (TD). This suggests that deformation along the TD becomes relatively more difficult with the increasing temperature. As temperature increases, deformation appears to become more difficult along the direction with the highest basal pole density. This then implies that, as the temperature rises, the deformation along the c-axis becomes harder than that along the $\langle$ a axis. It should be noted that the Lankford coefficient is expected to change as texture develops during deformation. The degree of variation is likely to depend on how much the basal pole figure distribution develops during deformation. However, under the conditions measured in this study, the majority of basal poles remained aligned closest to the ND following deformation. Thus, it is reasonable to infer that the increasing deformation temperature reduces the degree of strain accommodated along the $\langle\mathrm{c}\rangle$ axis than along the $\langle\mathrm{a}\rangle$ axis.

\section{MICROSTRUCTURAL EVOLUTION}

\section{A. Texture Evolution}

Texture was measured using EBSD. Surface preparation for EBSD (and XRD) consisted of grinding, diamond polishing ( 6,3 and $1 \mu \mathrm{m}$ diamond paste), etching ( 60 pct $\mathrm{H}_{2} \mathrm{O}, 5$ pct $\mathrm{HF}, 35$ pct $\mathrm{HNO}_{2}$ ), and final OPS polishing (5:1 ratio OPS: $\mathrm{H}_{2} \mathrm{O}_{2}$ ). EBSD mapping was carried out on a FEI Sirion Field Emission Gun Scanning Electron Microscope with an HKL EBSD system. EBSD Maps of $180 \times 230 \mu \mathrm{m}$ in dimension were acquired at a working distance of 10 to $15 \mathrm{~mm}$ using $20 \mathrm{kV}$ accelerating voltage.

EBSD texture measurements were undertaken using a step size of $5 \mu \mathrm{m}$ and 15 to 20 scans from several regions across each sample, sampling a total area of $0.8 \mathrm{~mm}^{2}$ and over 8000 grains. $\varphi_{1}$ sections at $\varphi_{1}=0 \mathrm{deg}, 30 \mathrm{deg}$, and $60 \mathrm{deg}$ are given in Figure 4 showing the texture after uniaxial compression to 0.07 along RD and ND. RD compression causes a strengthening of the $\{10 \overline{1} 3\}\langle 1 \overline{12} 0\rangle$ component visible at $\varphi_{1}=0, \Phi=20$ to 40 , and $\varphi_{2}=30$. At $573 \mathrm{~K}$ and $773 \mathrm{~K}\left(300{ }^{\circ} \mathrm{C}\right.$ and $500{ }^{\circ} \mathrm{C}$ ), the initially predominant $\{10 \overline{1} 3\}\langle 11 \overline{2} 0\rangle$ component shifts slightly to smaller $\Phi$ values. Compression along ND does not cause a large preferable strengthening of either of the two components (Figure 4). Instead, they both strengthen as the distribution of orientations moves to smaller $\Phi$ values. 

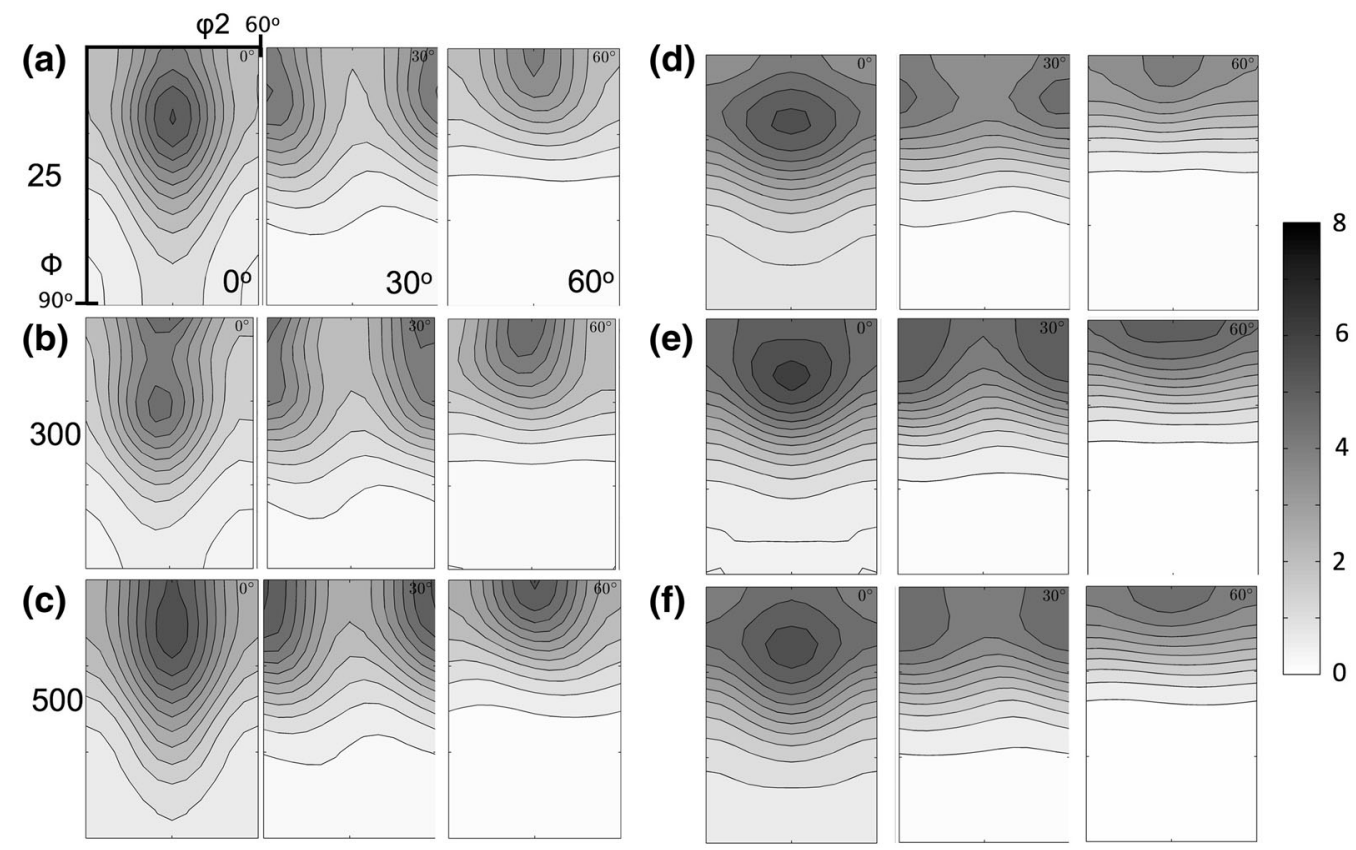

Fig. 4 - ODF $\varphi_{1}$ sections $(0 \mathrm{deg}, 30 \mathrm{deg}, 60 \mathrm{deg})$ for RD compression at $($ a $) 298 \mathrm{~K}\left(25^{\circ} \mathrm{C}\right),(b) 573 \mathrm{~K}\left(300{ }^{\circ} \mathrm{C}\right)$, and $(c) 773 \mathrm{~K}\left(500{ }^{\circ} \mathrm{C}\right)$; and $\mathrm{ND}$ compression at $(d) 298 \mathrm{~K}\left(25^{\circ} \mathrm{C}\right),($ e $) 573 \mathrm{~K}\left(300{ }^{\circ} \mathrm{C}\right)$, and $(f) 773 \mathrm{~K}\left(500^{\circ} \mathrm{C}\right)$.

\section{B. Intragranular Misorientation Development}

Detailed EBSD maps of $180 \times 230 \mu \mathrm{m}$ in dimension were acquired at a working distance of 10 to $15 \mathrm{~mm}$ using $20 \mathrm{kV}$ accelerating voltage and a step-size of $0.35 \mu \mathrm{m}$. Between 4 and 6 maps were acquired per specimen. The EBSD maps were analyzed to quantify the development of intragranular misorientation using two main parameters: GAM and nearest neighbor disorientations (misorientation angles/axis pairs between neighboring measurement positions). GAM values were calculated for each measurement point. This was done by calculating the disorientation angle between the average orientation (calculated using the method described in Cho et al. ${ }^{[19]}$ ) of a grain and the orientation at each position within that grain. The distribution of GAM provides information on the spread of orientations within a single grain. GAM values increase as regions of grains rotate away from the mean orientation, and thus can indicate the extent to which a grain is fragmented. Nearest neighbor orientations were used to indicate the main axis of misorientation in the grains, which can provide an indication of the main active slip system. ${ }^{[20]}$

Representative EBSD maps of the deformed microstructures are shown in Figure 5. Deformation twins are visible after compression at $298 \mathrm{~K}$ and $573 \mathrm{~K}$ $\left(25^{\circ} \mathrm{C}\right.$ and $\left.300{ }^{\circ} \mathrm{C}\right)$. The twins have been identified as $85 \mathrm{deg}\{10 \overline{1} 2\}\langle 10 \overline{1} 1\rangle$ tensile twins by comparing the misorientation relationship between the parent grain and the twin with the characteristic relationships of the commonly observed twin systems. ${ }^{[21]}$ Unexpectedly, the area fraction of twins observed during RD compression is higher at $573 \mathrm{~K}\left(300{ }^{\circ} \mathrm{C}\right)$ than that at $298 \mathrm{~K}\left(25^{\circ} \mathrm{C}\right)$ after 0.07 strain. At $773 \mathrm{~K}\left(500{ }^{\circ} \mathrm{C}\right)$, only a few twins can be seen after either RD or ND compression. The maps clearly show that the grains have developed spatial variations in orientation, that is, they have started to break up.

The misorientation axis of neighboring misorientations can give an indication of the active slip systems. The method of extracting and plotting the In-Grain Misorientation Axis (IGMA) used here is the same as that explored by Chun et al. ${ }^{[20]}$ The method is limited, as it cannot be used to discriminate clearly between different $\langle\mathrm{c}+\mathrm{a}\rangle$ slip modes or basal slip modes. However, it can show clearly whether prismatic slip or nonprismatic slip is dominant within a grain. This discrimination is possible as a result of prismatic slip having a distinct misorientation axis about the $\langle 0001\rangle$ axis. Basal and pyramidal $\langle\mathrm{c}+\mathrm{a}\rangle$ slip axis distributions lie close to $\langle$ uvt 0$\rangle$, which is $90 \mathrm{deg}$ from the $\langle 0001\rangle$ axis that is characteristic of prismatic slip. Therefore, peaks in axis distributions due to prismatic slip are clearly distinguishable from peaks caused by basal or pyramidal slip.

Distributions of these axes were calculated from the specimens compressed to 0.07 at each of the three temperatures and two loading directions (six specimens in total). Misorientation axes were extracted from the 10 pct of grains with the highest prismatic Schmid factors and the $10 \mathrm{pct}$ of grains with the lowest (Figure 6). In most cases, the misorientation peak is strongly aligned with $\langle 0001\rangle$, the characteristic axis for prismatic slip. This is to be expected as prismatic slip is considered by far the easiest slip system in $\mathrm{Zr}$ and its alloys. ${ }^{[21]}$ In a few cases, the $\langle$ uvt 0$\rangle$ directions are more prevalent: at $298 \mathrm{~K}$ and $573 \mathrm{~K}\left(25^{\circ} \mathrm{C}\right.$ and $\left.300{ }^{\circ} \mathrm{C}\right)$ in the grains poorly oriented for prismatic slip in RD compression (Figures 6(d) and (e)) and at $298 \mathrm{~K}\left(25^{\circ} \mathrm{C}\right) \mathrm{ND}$ compression (Figure 6(j)). This suggests that at $298 \mathrm{~K}$ 

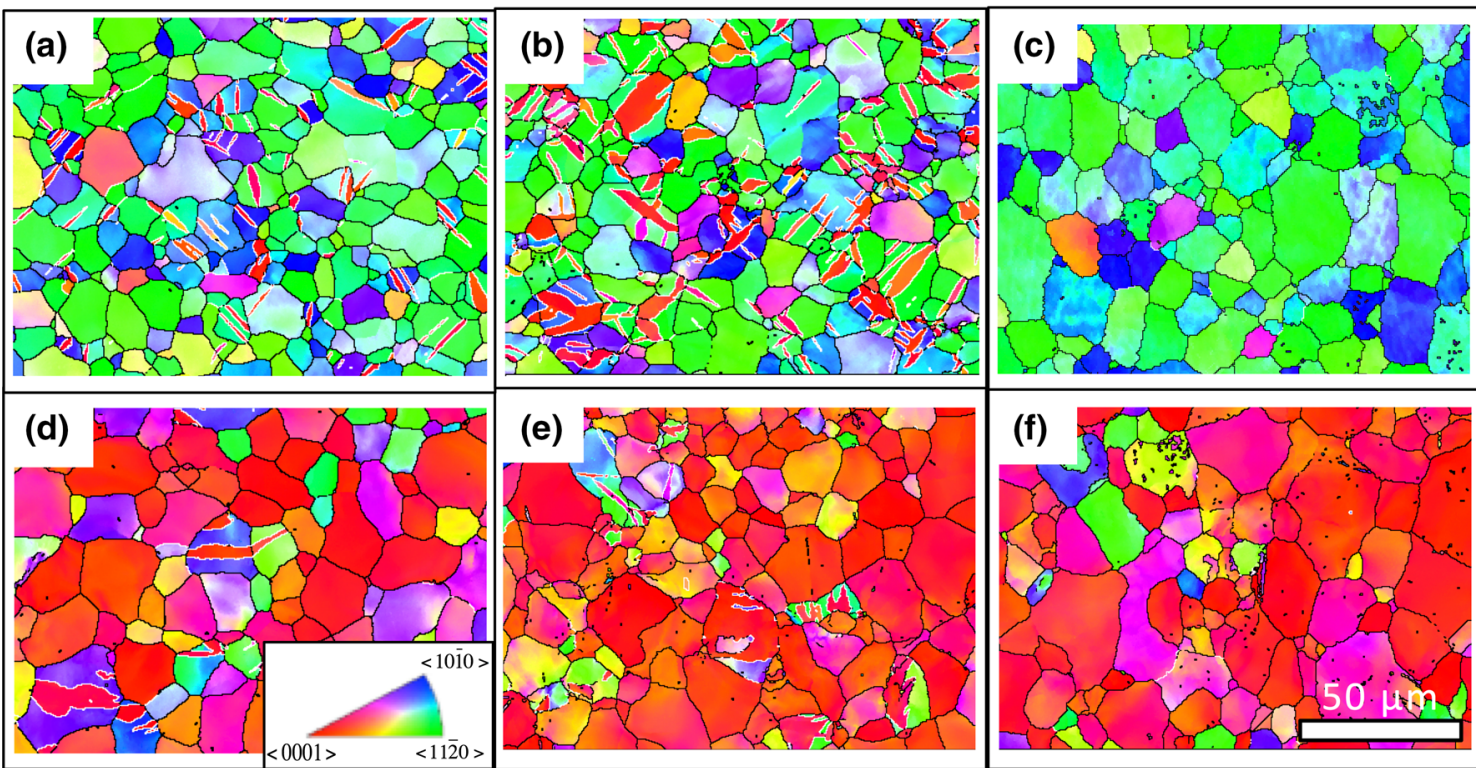

Fig. 5-Microstructural maps acquired after 0.07 compressive strain. Samples shown include those strained along the RD at (a) $298 \mathrm{~K}\left(25{ }^{\circ} \mathrm{C}\right)$, (b) $573 \mathrm{~K}\left(300{ }^{\circ} \mathrm{C}\right)$, and $(c) 773 \mathrm{~K}\left(500{ }^{\circ} \mathrm{C}\right)$; and $\mathrm{ND}$ at $(d) 298 \mathrm{~K}\left(25^{\circ} \mathrm{C}\right),(e) 573 \mathrm{~K}\left(300{ }^{\circ} \mathrm{C}\right)$, and $(f) 773 \mathrm{~K}\left(500{ }^{\circ} \mathrm{C}\right)$.
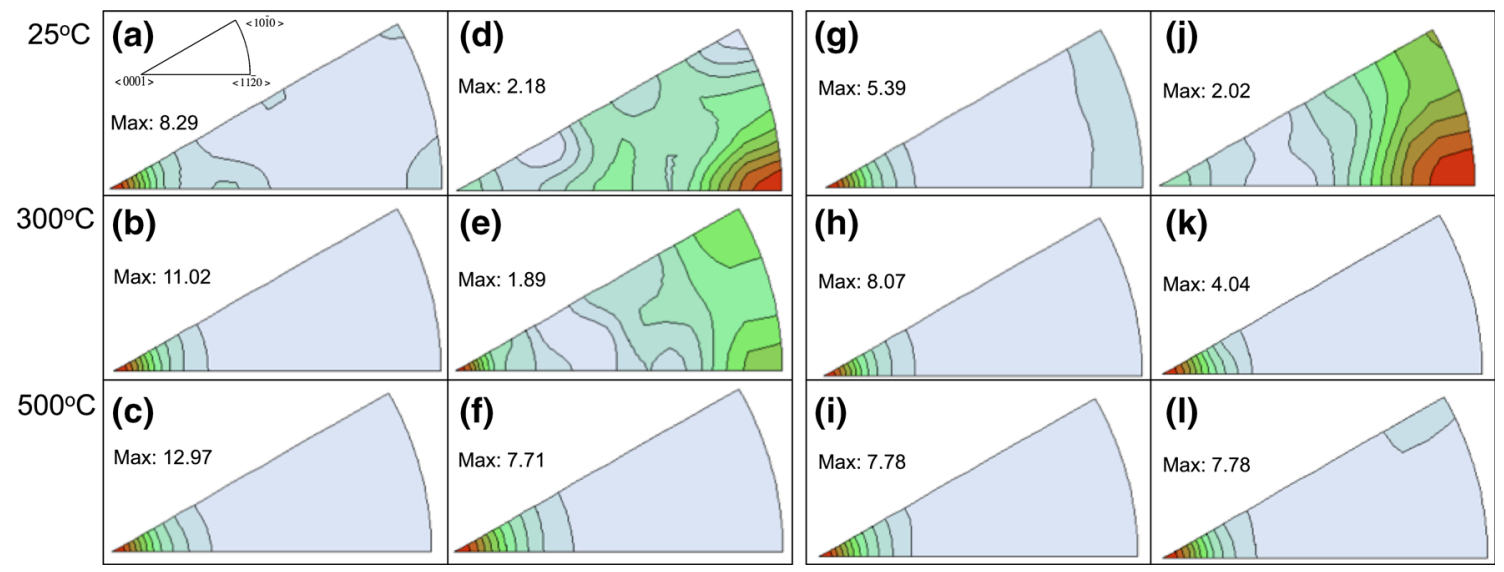

Fig. 6-In-Grain Misorientation Axis distributions for 10 pct of grains best orientated for prismatic slip $(a-c$ and $g-i)$ and 10 pct of grains worst orientated for prismatic slip $(d-f$ and $j-l)$ during RD (a-f) and ND $(\mathrm{g}-1)$ compressions at $298 \mathrm{~K}\left(25{ }^{\circ} \mathrm{C}\right), 573 \mathrm{~K}\left(300{ }^{\circ} \mathrm{C}\right)$, and $773 \mathrm{~K}\left(500{ }^{\circ} \mathrm{C}\right)$.

$\left(25^{\circ} \mathrm{C}\right)$ and perhaps at $573 \mathrm{~K}\left(300{ }^{\circ} \mathrm{C}\right)$, some of the grains that are least well orientated for prismatic slip undergo an increased amount of deformation via nonprismatic slip systems. However, this is not the case at $773 \mathrm{~K}\left(500{ }^{\circ} \mathrm{C}\right)$ (Figures 6(j) and (1)). It should be noted that although IGMA may enable conclusions about the dominant slip systems that are active in a particular grain or set of grains, it cannot provide unambiguous information regarding secondary slip activity. Therefore, although these results strongly imply that prismatic slip is dominant at $773 \mathrm{~K}\left(500{ }^{\circ} \mathrm{C}\right)$, this does not mean that non-prismatic systems are inactive - only that their influence is obscured by that of the dominant system. The influence of secondary systems can be more easily studied by tracking the orientation change from the initial to the deformed state. This is explored in the following section.

\section{Orientation Tracking}

The analysis of texture evolution and misorientation analysis suggest that prismatic slip dominates during deformation at $773 \mathrm{~K}\left(500{ }^{\circ} \mathrm{C}\right)$. In order to observe directly how the grains of the two main texture components break up under the action of prismatic slip, a selected region was tracked, using EBSD, during compressive strain along the $\mathrm{RD}$, to a maximum strain of 0.17 . This analysis is not possible ex situ since the starting grain orientation is not known.

To minimize sample oxidation, the tests were undertaken in a vacuum of approximately $1.2 \times 10^{-4} \mathrm{~atm}$ and heated using resistance heating in a Gleeble 3500 mechanical testing system. Despite these precautions, some surface oxidation did take place. As a result, the post-deformation EBSD quality was relatively poor, 
with an indexing rate of only 58 pct. Only indexed data points were used in the analysis. Cleaning of the data was used only to aid identification of the grains postdeformation. The size of the mapped region was $350 \times 460 \mu \mathrm{m}^{2}$, and the number of grains measured in the initial EBSD scan was 1473.

A section of the mapped region is shown in Figure 7 before and after RD compression at $773 \mathrm{~K}\left(500{ }^{\circ} \mathrm{C}\right)$. Misorientations were calculated between the initial orientation of each grain and the orientations within the grain after deformation. The misorientation angle and calculated axes distributions are shown in Figure 8. The misorientation angle distribution between the initial and final state reveals that orientations within the grains with $\langle 10 \overline{1} 0\rangle / / \mathrm{RD}$ rotate by a greater degree than those with $\langle 11 \overrightarrow{20}\rangle / /$ RD. This suggests that the latter rotate less, or are more stable under RD compression, which is in agreement with the observed texture evolution. The $\langle 11 \overline{20}\rangle / /$ RD grains do still appear to show misorientation away from their original orientations, that is, all grains rotate to some extent. All grains can be expected to undergo some degree of rotation during deformation,

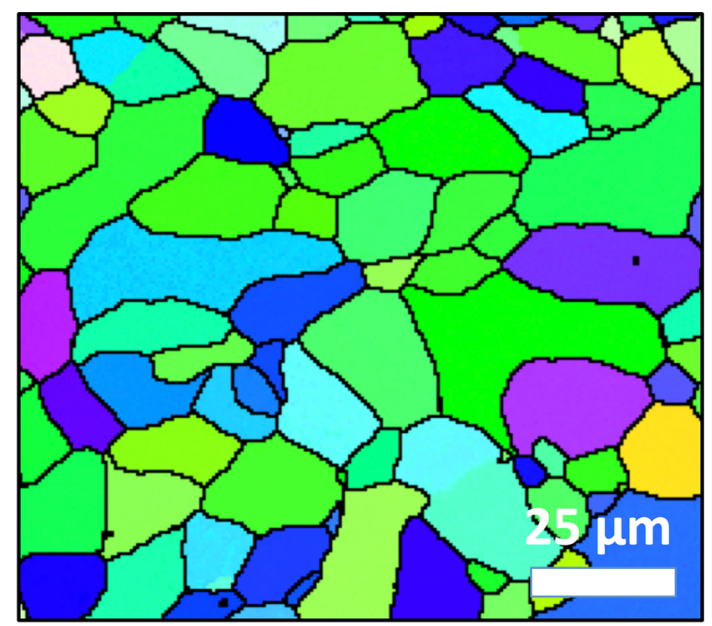

(a)

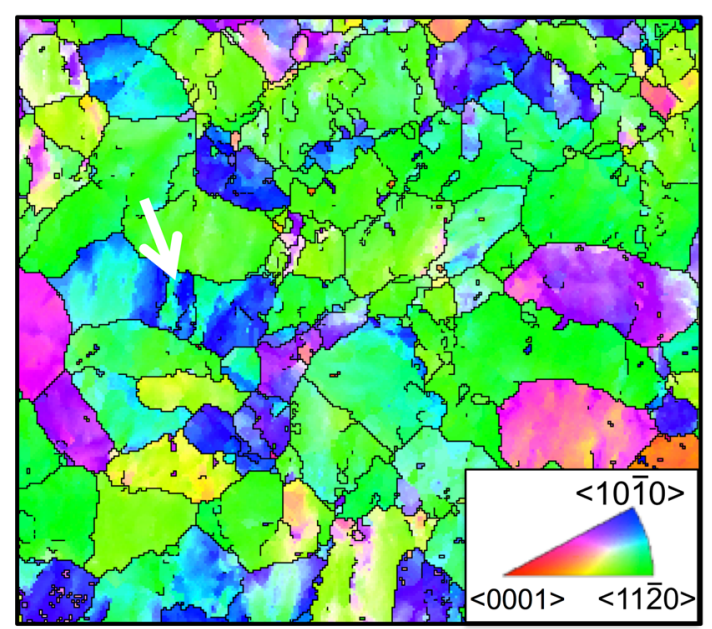

(b)

Fig. 7-Selected region of larger microstructural map before $(a)$ and after $(b)$ compressive strain along the RD. The latter has been partly reconstructed to allow for easier visualization of the microstructure. either as a result of slip induced lattice rotation or due to rigid body rotation from the influence of neighboring grain interactions.

The distribution of GAM values calculated from the deformed grains alone is shown in Figure 8(d). There is a greater spread of orientations in the deformed $\langle 10 \overline{1} 0\rangle / / \mathrm{RD}$ grains than the deformed $\langle 11 \overline{2} 0\rangle / / \mathrm{RD}$ grains. This might appear like a small effect, but it is clearly significant since, as will be discussed later, both orientations have the identical starting slip activities.

The axis about which the grain rotations have taken place reveals that the grains with $\langle 10 \overline{1} 0\rangle / / \mathrm{RD}$ rotate mainly about the $\langle 0001\rangle$ axis. As mentioned previously, this misorientation axis is characteristic of prismatic slip. The $\langle 11 \overline{2} 0\rangle / / \mathrm{RD}$ rotate mainly about the $\langle 10 \overline{1} 0\rangle$ axis although there is a spread about $\langle$ uvt 0$\rangle$. This peak may be caused by a rotation of the grain about the transverse direction (which is parallel to $\langle 10 \overline{1} 0\rangle$ ), a direct consequence of the lack of constraint at the surface of the sample. In fact, the misorientation axis plot for the $\langle 10 \overline{1} 0\rangle / / \mathrm{RD}$ grains also show a peak for rotations about the transverse direction (in this case the $\langle 11 \overline{2} 0\rangle$ axis). Alternatively, the $\langle 10 \overline{1} 0\rangle$ axis has been said to be characteristic of basal slip; however, the co-activation of $\langle c+a\rangle$ slip variants ${ }^{[20]}$ or a combination of all main slip systems could potentially generate similar orientation changes.

The important finding is that the grain distortion in the $\langle 11 \overline{2} 0\rangle / / \mathrm{RD}$ grains, which is more stable, is not about the $\langle 0001\rangle$ axis despite the fact that prismatic slip must dominate. CPFEM simulations have also shown differences between the rotation axis distributions of the two fibers. That for $\langle 10 \overline{1} 0\rangle / /$ RD fiber showed qualitative agreement with the experimentally derived data (Figure 8). The simulated $\langle 11 \overline{2} 0\rangle / / \mathrm{RD}$ fiber rotation axis distribution, however, showed a more random rotation axis distribution than that shown in Figure 8.

\section{Influence of Temperature and Loading Direction on Grain Breakup}

Having determined the basic characteristics of grain breakup, one can now look at how it is affected by temperature and loading direction. The GAM distributions from samples strained to 0.07 , corresponding to the EBSD maps shown in Figure 5, were calculated for the two different loading directions at the three different temperatures: room temperature, $573 \mathrm{~K}$ and $773 \mathrm{~K}$ $\left(300{ }^{\circ} \mathrm{C}\right.$ and $\left.500{ }^{\circ} \mathrm{C}\right)$. The strain chosen for this analysis is a compromise between introducing sufficient deformation to see its effect on the microstructural evolution while keeping the strain low enough in order to avoid significant twinning, which is important to allow comparisons between samples compressed at different temperatures. The GAM values from the twinned grains (which do not exceed an area fraction of $14 \mathrm{pct}$ ) were not included in the GAM distributions shown.

Figure 9(a) clearly shows that there is a significant difference between the GAM distributions for samples compressed along different loading directions at $773 \mathrm{~K}$ $\left(500{ }^{\circ} \mathrm{C}\right)$. The distributions in (Figure $9(\mathrm{~b})$ ) are described using the median and the upper and lower 


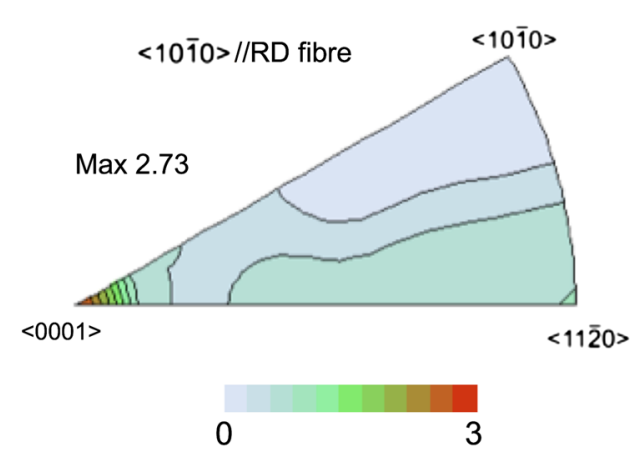

(a)

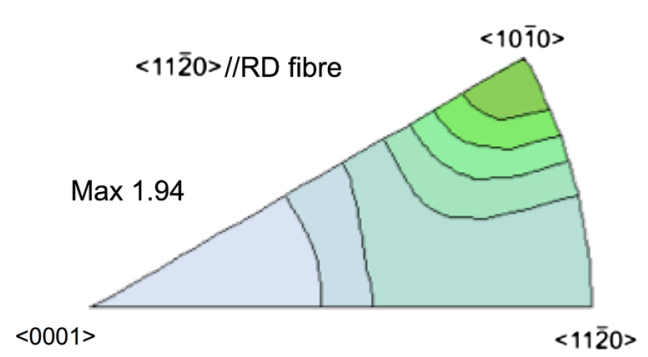

(b)

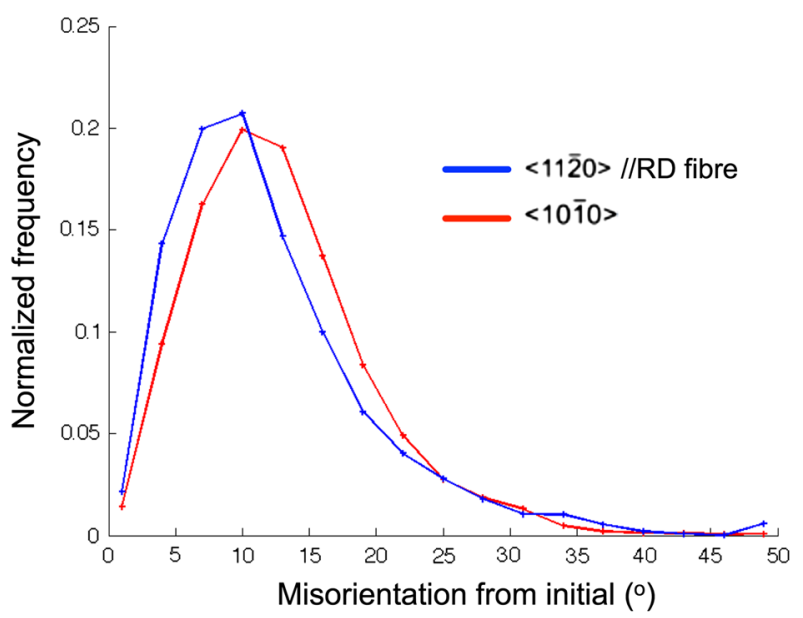

(c)

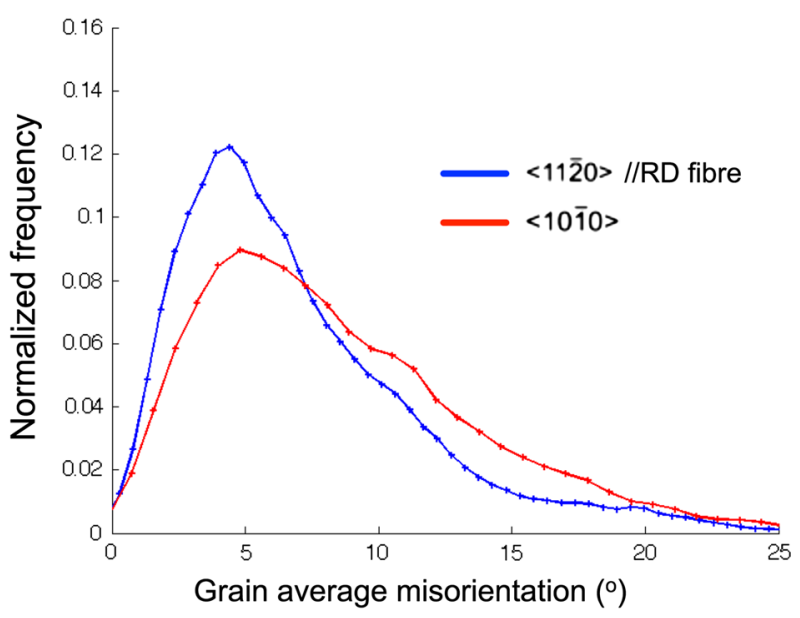

(d)

Fig. 8-Misorientation axis distributions between the initial and final orientations for the grains of $(a)$ the $\langle 10 \overline{1} 0\rangle / / \mathrm{RD}$ fiber and $(b)$ the $\langle 11 \overline{2} 0\rangle$ fiber. (c) Misorientation angle distribution between the initial and final orientations for the two fibers and (d) Grain average misorientation calculated from the deformed grain data for grains of the two fibers.

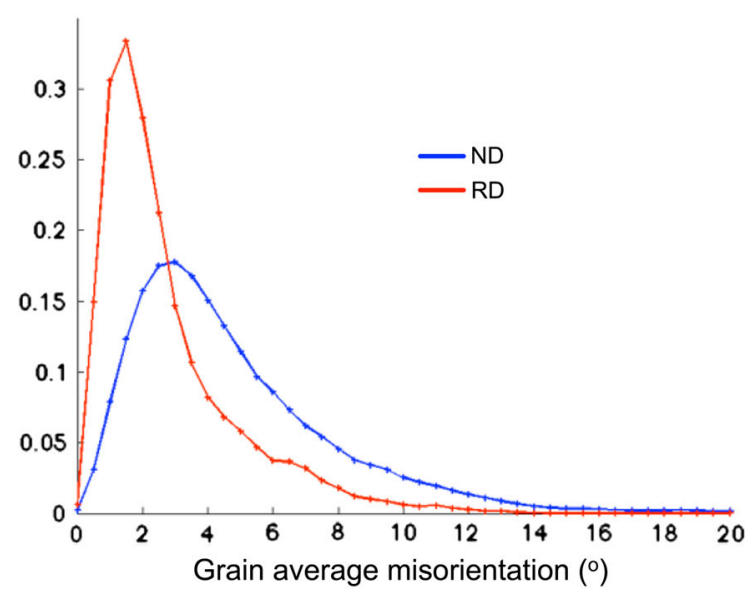

(a)

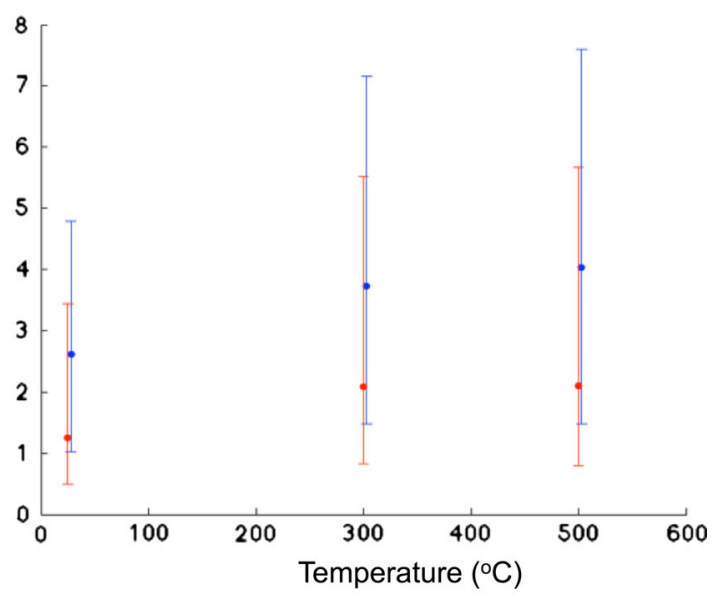

(b)

Fig. 9-(a) Grain average misorientation distributions exhibiting the difference in spread between the two directions taken from RD and ND compression at $773 \mathrm{~K}\left(500{ }^{\circ} \mathrm{C}\right)$ after 0.07 strain. (b) The median of the RD (red) and ND (blue) GAM distributions at three temperatures. The upper and lower quartiles of the distributions are shown as error bars (Color figure online). 
quartiles of the GAM values calculated. The upper and lower quartiles are plotted as error bars. It can be seen that both the median GAM and its spread (interquartile range) increase with temperature for both RD and ND compression (Figure 9(b)), with the greatest increase occurring between $298 \mathrm{~K}$ and $573 \mathrm{~K}\left(25^{\circ} \mathrm{C}\right.$ and $300{ }^{\circ} \mathrm{C}$ ). The GAM spread for the ND compression specimens is always larger than for the RD specimens. This suggests that the breaking-up of the grains is more pronounced in the case of ND compression and that the amount of breakup increases as temperature increases. Since the activity of the available deformation modes can be affected by both changing the deformation temperature and the loading direction, we have used crystal plasticity modeling (CPFEM) to explore how the activity of the main slip modes may influence the GAM distributions.

\section{CRYSTAL PLASTICITY FINITE ELEMENT MODELING}

The CPFEM code used in this study was originally described by Bate. ${ }^{[22]}$ It has been used previously for lattice strain prediction ${ }^{[23]}$ and texture simulation ${ }^{[24]}$ in IF steel. Deformation is imposed in small strain increments. Shear strain rates on all slip systems are calculated at each material point (integration point) using constitutive equations. Overall equilibrium is attained using the strains and stresses calculated at each integration point. Slip is assumed to be weakly rate sensitive. The slip rates and shear stresses are related through the viscoplastic relation:

$$
\frac{\dot{\gamma}}{\dot{\gamma}_{0}}=\left(\frac{\tau}{\tau_{0}}\right)^{\frac{1}{m}}
$$

where $\dot{\gamma}$ is the slip rate, $\tau$ is the resolved shear stress, $\tau_{0}$ is the instantaneous slip resistance, and $m$ is the rate sensitivity. The macroscopic rate sensitivity of zirconium during deformation along the RD lies within the range of 0.02 and 0.06 above room temperature. ${ }^{[25]}$ The value used for $m$ in this work was kept constant at 0.02 .

Slip systems included into the model were prismatic $\{10 \overline{1} 0\}\langle 11 \overline{2} 0\rangle$, basal $\{0001\}\langle 11 \overline{2} 0\rangle$, and pyramidal $\{10 \overline{1} 1\}\langle 11 \overline{23}\rangle$. Using intergranular strain measurements and modeling, $\mathrm{Xu}^{[26]}$ has shown that basal slip should be included into crystal plasticity modeling of a similar alloy, Zircaloy-2. Twinning is not included as a deformation mode in this model. Early studies on single crystals showed that the relative activity of the available systems changes with temperature. ${ }^{[27,28]}$ In the current study, the Lankford coefficients measured after compression testing suggest that deformation along the $\langle\mathrm{c}\rangle$ axis becomes more difficult as temperature increases. The simplest explanation for this behavior is that $\langle\mathrm{c}+\mathrm{a}\rangle$ slip becomes relatively harder than prismatic and basal slip ( $\langle\mathrm{a}\rangle$ slip). We therefore ran a series of simulations with the increasing $\mathrm{CRSS}_{\langle\mathrm{c}+\mathrm{a}\rangle} / \mathrm{CRSS}_{\langle\mathrm{a}\rangle}$ ratio in order to reproduce the observed increase in anisotropy with temperature and predict its impact on grain breakup. The range of CRSS ratios used was between 1 and 10 ,

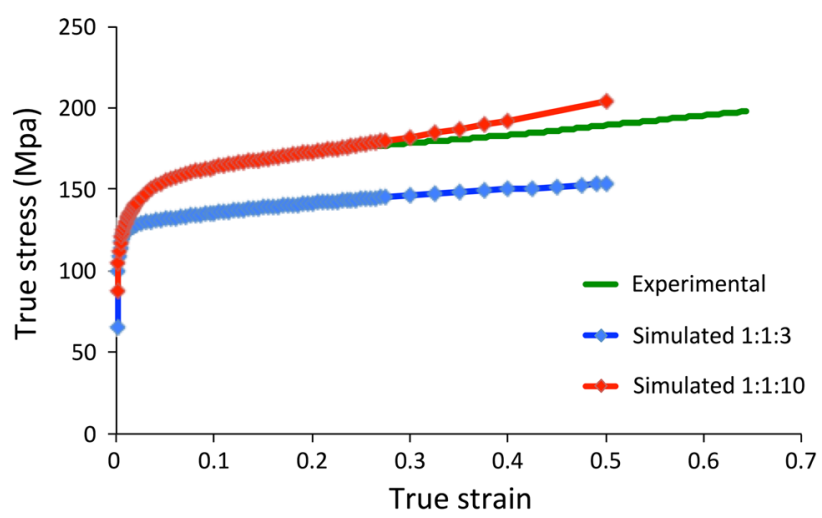

(a)

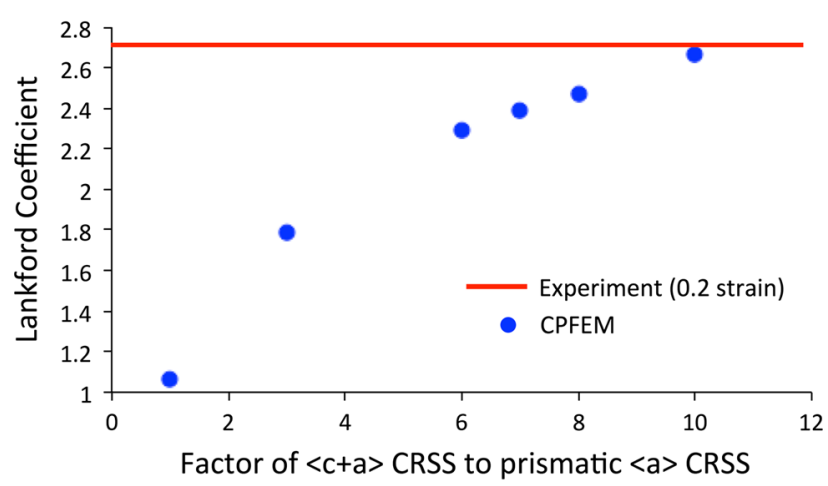

(b)

Fig. 10 - (a) Comparison of experimental flow curve of RD compression at $773 \mathrm{~K}\left(500{ }^{\circ} \mathrm{C}\right)$ and simulated flow curves using $\langle\mathrm{a}\rangle:\langle\mathrm{c}+\mathrm{a}\rangle$ of 1:1:3 and 1:1:10, (b) Comparison of the experimental Lankford coefficient measured at 0.2 strain (red line) with simulated values after an equivalent strain using different $\langle\mathrm{a}\rangle:\langle\mathrm{c}+\mathrm{a}\rangle$ ratios. The horizontal axis scale represents the number of times the $\langle c+a\rangle$ slip CRSS is harder than that used for $\langle a\rangle$ slip (Color figure online).

whereas the typical CRSS ratio used in crystal plasticity simulations of a similar alloy Zircaloy- 2 is between 3 and $4{ }^{[26,29]}$ The ratio of 1:1 was included as a means of exploring the result of $\langle c+a\rangle$ getting relatively easier with the increasing temperature, which was suggested in previous work. ${ }^{[27,30]} \mathrm{A}$ ratio of $10: 1$ gives a better fit to the flow curves at $773 \mathrm{~K}\left(500{ }^{\circ} \mathrm{C}\right)$, than a ratio of 3 to 4 , as well allowing better predictions of Lankford coefficients (Figure 10) and texture for RD compression.

The remaining single crystal slip parameters used in the CPFEM carried out in this study were derived through obtaining a reasonable match between the simulated and experimental stress strain curves, Lankford coefficients, and texture evolution data. The slip parameters used are given in Table I.

\section{A. Polycrystalline Deformation Modeling}

The polycrystalline aggregates modeled were made up of $10 \times 10 \times 1020$-node isoparametric brick elements, each with eight integration points. Each element was assigned an orientation, and the chosen set of 1000 orientations represented the initial texture. Models were run to simulate compression along RD and compression along ND. The orientations at the integrations points 
were then used to calculate the GAM distributions for each grain, so that they could be compared directly with the experimental data.

The GAM spread calculated from the simulations of $\mathrm{RD}$ compression is shown alongside the equivalent experimental data in Figure 11 at two different strain levels (0.07 and 0.2 true strain). Using a CRSS ratio $(\langle\mathrm{c}+\mathrm{a}\rangle /\langle\mathrm{a}\rangle)$ of 10 , the model clearly captures the greater spread in GAM exhibited by the $\langle 10 \overline{1} 0\rangle / / \mathrm{RD}$ grains compared with grains belonging to the $\langle 11 \overline{2} 0\rangle / / \mathrm{RD}$ fiber. Increasing the number of elements representing each grain was investigated, and it was found to give similar GAM distributions. The primary difference was an increase in the breadth of the GAM distribution as the number of elements used per grain rose. In addition, using more elements per grain reinforced the trend of increasing misorientation with the increasing slip anisotropy.

Figure 12 shows that the predicted GAM spread for $\mathrm{ND}$ is larger than that of RD compression, which was observed experimentally (Figure 9(b)). However, the predicted difference between the two directions is smaller than that found experimentally. The influence of changing the relative slip activities upon the GAM distribution can be seen in Figure 12. The median values and upper quartile of the GAM distributions increase as $\langle\mathrm{c}+\mathrm{a}\rangle$ slip becomes relative harder than $\langle\mathrm{a}\rangle$ slip. The difference between ND and RD compression also increases as the CRSS ratio rises.

Table I. Slip Parameters Used in This Study

\begin{tabular}{|c|c|}
\hline Parameter & Value \\
\hline CRSS prismatic slip & $\tau_{0}=41, \tau_{\mathrm{s}}=55 \mathrm{MPa}$ \\
\hline CRSS pyramidal slip & $\tau_{0}=41$ to $410, \tau_{\mathrm{s}}=55$ to $550 \mathrm{MPa}$ \\
\hline CRSS basal slip & $\tau_{0}=41, \tau_{\mathrm{s}}=55 \mathrm{MPa}$ \\
\hline$\theta_{\mathrm{o}}$ & $\begin{array}{c}\text { prism }=1000 \mathrm{MPa} \text {, basal }= \\
1000 \mathrm{MPa}, \text { pyr }=4 \mathrm{MPa}\end{array}$ \\
\hline$\theta_{\mathrm{IV}}$ & $\begin{aligned} \text { prism } & =0 \mathrm{MPa}, \text { bas }=0 \mathrm{MPa} \\
\text { pyr } & =0 \mathrm{MPa}\end{aligned}$ \\
\hline$\alpha$ & prism $=2.7$, basal $=2.7$, pyr $=3.6$ \\
\hline
\end{tabular}

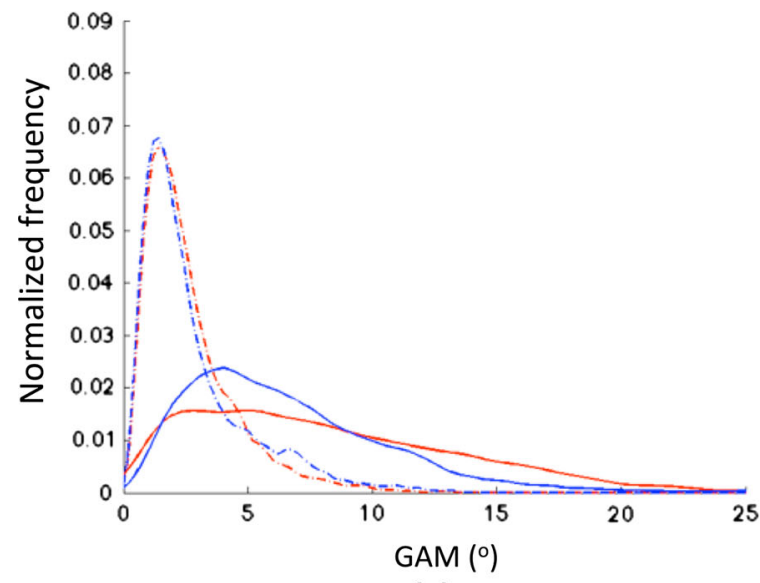

(a)

\section{B. Perturbed Grain Modeling}

In a "perturbed" grain simulation, the compression of a single crystal is modeled using the same parameters used for the polycrystalline model but rather than using the same orientation for all integration points in a grain, the main orientation is "perturbed," and the integration points are orientations within a small range of the mean orientation. This spread in orientation allows the grain to develop internal stress and strain gradients to accommodate the imposed constraints by providing a kind of substructure. Although recrystallized materials do not usually have such initial perturbed microstructures, it can be argued that the impingement of neighboring grains leads to the development of local stress variations, which combined with the (related) development of deformation substructures, lead to the development of mosaicity within grains. Here, we used CPFEM simulations of "perturbed" grains to study the

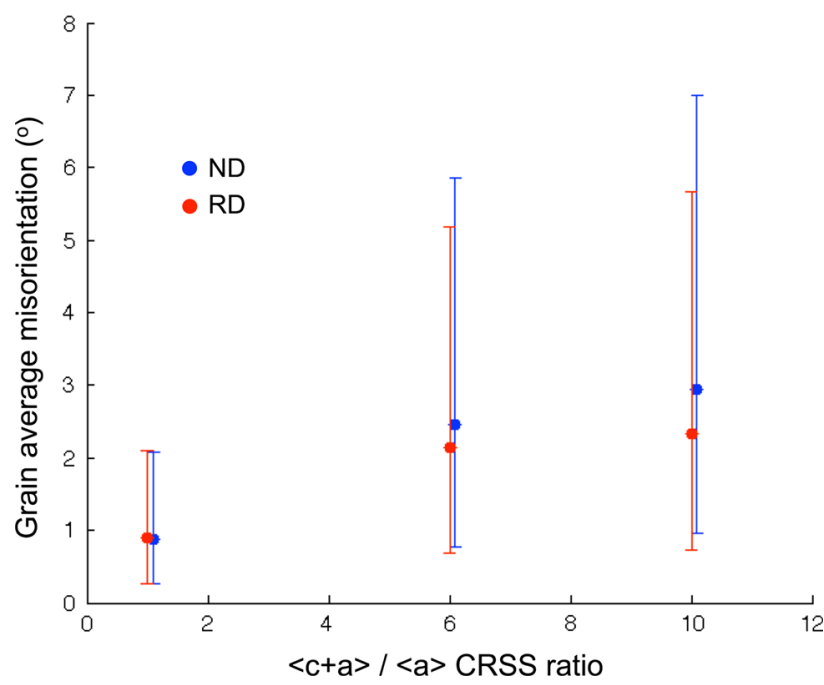

Fig. 12-Variation of median GAM with $\langle\mathrm{c}+\mathrm{a}\rangle /\langle\mathrm{a}\rangle$ ratio for both RD and ND compressions. Upper and lower quartiles of GAM distributions shown as error bars.

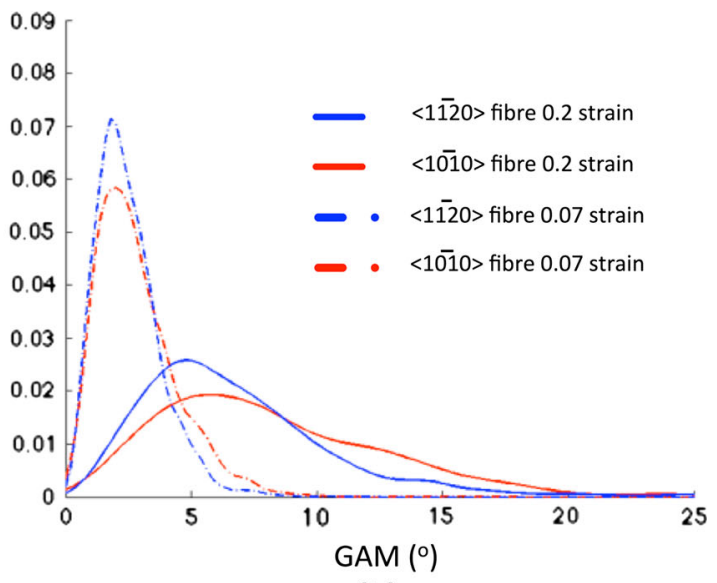

(b)

Fig. 11-GAM distributions in the two predominant fibers at 0.07 and 0.2 strains after RD compression at $773 \mathrm{~K}\left(500{ }^{\circ} \mathrm{C}\right)$. (a) Calculated data from EBSD; $(b)$ equivalent data calculated from CPFEM. 


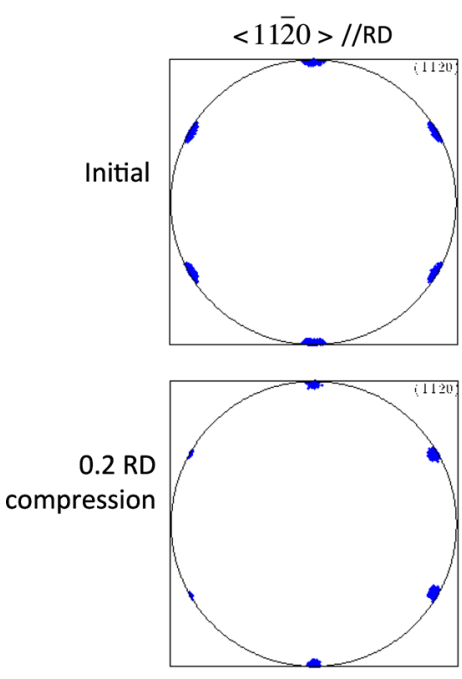

(a)
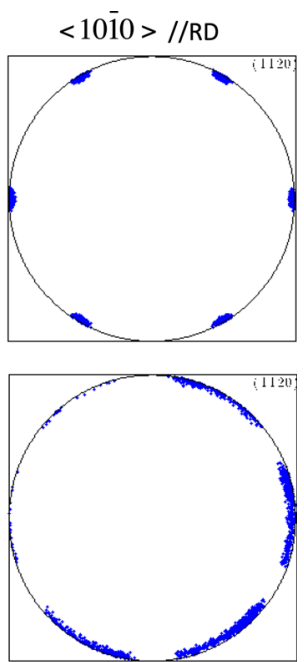

(b)
Fig. 13-Perturbed grain model results. (1120) poles of the initial and strained ( 0.2 strain) orientations of the perturbed grain models

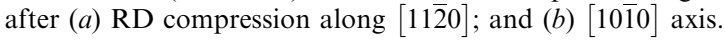

two fibers $(\langle 11 \overline{2} 0\rangle / / \mathrm{RD}$ and $\langle 10 \overline{1} 0\rangle / / \mathrm{RD})$, by randomly perturbing their orientation by 5 deg.

The results of the "perturbed" grain simulations are illustrated in Figure 13, where the original and final distributions of orientations are plotted on $11 \overline{2} 0$ pole figures for both simulations. These results clearly show that whereas for the $[11 \overline{2} 0]$ grain the spread in orientations narrows with deformation, it increases significantly for the $[10 \overline{1} 0]$ grain. This increase in spread occurs by rotation about [0001], which is consistent with the one being induced by prismatic slip and in agreement with the results of the EBSD misorientation axis analysis.

This increase in spread can also be quantified by GAM. The GAM calculated for the perturbed grains is shown in Figure 14 alongside GAM distributions of grains within these fibers during simulated RD and ND compressions. The perturbed grain compressed along the $[10 \overline{10}]$ direction has a significantly larger spread in orientation (median GAM of 5.2) than that compressed along the $[11 \overline{2} 0]$ direction (median of 0.3 ). The latter actually has a smaller spread of orientations than the input orientation spread. The simulation of ND compression upon a perturbed grains of the two fibers

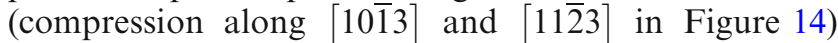
produces similar GAM spreads both having a median of $\sim 3$.

\section{DISCUSSION}

\section{A. Mechanical Behavior: Effect of Temperature and Loading Direction}

The higher yield stress for ND compression than that for $\mathrm{RD}$ compression is a direct consequence of the texture of the material and the consequential lower Schmid factor for prismatic slip. The relatively higher

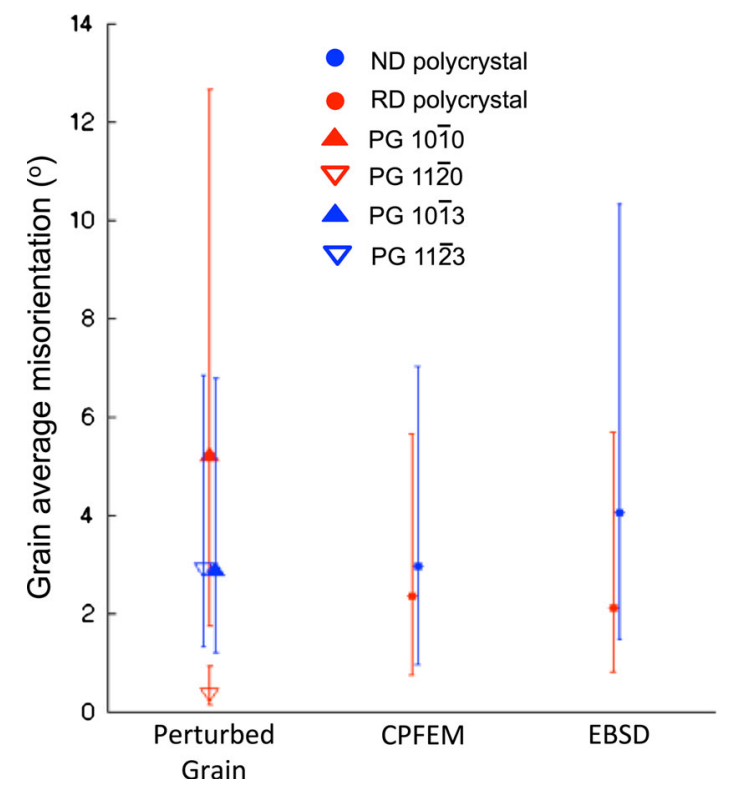

Fig. 14-Median GAM calculated from EBSD, polycrystal CPFEM and perturbed grain CPFEM. The upper and lower quartiles of the distributions are shown as error bars.

CRSS of $\langle c+a\rangle \operatorname{slip}^{[21]}$ means that it is less likely to play as big a role as prismatic slip during yielding. This yield anisotropy, the strong anisotropy in the transverse strains, and the misorientation angle analysis all point to the idea that prismatic slip dominates deformation in the early stages.

Therefore, the dramatic drop in flow stress with increasing temperature is likely to be caused by the temperature sensitivity of prismatic $\langle\mathrm{a}\rangle$ slip, which is well known and has been attributed to a number of phenomena, including the change in strength of solute pinning $^{[28,31]}$ or even simply to the variation of the lattice resistance to slip. ${ }^{[32]}$

The changes in Lankford coefficient with temperature shown in Figure 3 suggest that the difference in CRSS between $\langle a\rangle$ and $\langle\mathrm{c}+\mathrm{a}\rangle$ slip increases with the temperature. Since twinning also contributes to the deformation strain and the amount of twinning changes with temperature, it could be argued that the increasing anisotropy is a consequence of lower twinning activity. There are two arguments against this. First, the twin volume fraction in the samples in which the Lankford coefficients were measured was small $(<14 \mathrm{pct})$ as can be seen in Figure 5 and was actually greater at $573 \mathrm{~K}$ $\left(300{ }^{\circ} \mathrm{C}\right)$ than that at $298 \mathrm{~K}\left(25^{\circ} \mathrm{C}\right)$ (Figures 5(a) and (b)). Therefore, if twinning were responsible, one would expect a reversal in the observed trend. Second, even when twinning is heavily active, the amount of shear it contributes is much smaller than that contributed by slip. This was shown by McCabe et al. ${ }^{[33]}$ who observed that after 17 pet compressive strain of high-purity $\mathrm{Zr}$, only 20 pct of the shear was accommodated by twinning, despite a large twin area fraction of 45 pct. Therefore, we believe that the change in anisotropy with temperature is attributed to differences in the relative activities of slip modes and not to twinning and 
that $\langle\mathrm{c}+\mathrm{a}\rangle$ slip becomes relatively more difficult than $\langle\mathrm{a}\rangle$ slip as the temperature increases.

The IGMA axis distributions from the grains with lowest prismatic Schmid factor during ND compression (Figures 6(j) through (1)) show the dominant misorientation axis to be near [uvt0]. This implies that nonprismatic slip is more active at $298 \mathrm{~K}\left(25^{\circ} \mathrm{C}\right)$ than that at $773 \mathrm{~K}\left(500{ }^{\circ} \mathrm{C}\right)$. Assuming this non-prismatic slip to be pyramidal $\langle\mathrm{c}+\mathrm{a}\rangle$ slip supports our idea that $\langle\mathrm{a}\rangle$ and $\langle\mathrm{c}+\mathrm{a}\rangle$ slips are more similar (and thus $\langle\mathrm{c}+\mathrm{a}\rangle$ is more readily activated) at room temperature (RT) than at $773 \mathrm{~K}\left(500{ }^{\circ} \mathrm{C}\right)$. This does not mean that $\langle\mathrm{c}+\mathrm{a}\rangle$ slip is easier at RT than at $773 \mathrm{~K}\left(500{ }^{\circ} \mathrm{C}\right)$. This is clearly not true. All that is required is that the CRSS for $\langle c+a\rangle$ slip drops more slowly or at the same rate with temperature than that for prismatic slip.

The suggestion that $\langle\mathrm{c}+\mathrm{a}\rangle$ slip becomes relatively harder than $\langle a\rangle$ slip as temperature increases is not made lightly, as it contradicts single crystal CRSS measurements ${ }^{[27]}$ and data fitted to flow curves and texture data. $^{[30]}$ It is important to note, however, that these studies ${ }^{[27,30]}$ were carried out on high purity zirconium, which has $<50$ ppm oxygen. ${ }^{[34]}$ Soo $^{[28]}$ showed that the presence of oxygen in zirconium hardens prismatic slip and makes it significantly more temperature sensitive. Between $77 \mathrm{~K}$ and $473 \mathrm{~K}\left(-196{ }^{\circ} \mathrm{C}\right.$ and $\left.200{ }^{\circ} \mathrm{C}\right)$, Soo showed that prismatic slip in their lowest purity alloy (2000 ppm O) became easier by a factor 5.6 whereas the highest purity alloy (135 ppm O) became easier by a factor of 2.5. These finding are supported by calculations using a hard sphere model by Churchman, which predicted that the presence of oxygen will harden prismatic slip more significantly than pyramidal $\langle c+a\rangle$ slip. ${ }^{[35]}$ The alloy used in our study is a commercial alloy containing between 1000 and $1400 \mathrm{ppm}$ oxygen. The comparatively high oxygen content may cause the relative activities of $\langle a\rangle$ and $\langle\mathrm{c}+\mathrm{a}\rangle$ slip systems to be significantly different from those reported in studies using high-purity $\mathrm{Zr}$, and thus could explain our unusual result. The consequences of a variation in the relative slip activities upon the microstructural evolution are discussed later.

\section{B. The Mechanism of Grain Breakup by Prismatic Slip}

At $773 \mathrm{~K}\left(500{ }^{\circ} \mathrm{C}\right)$, prismatic slip dominates, and both textural evolution and misorientation analysis between the initial and the deformed states show that the $\langle 11 \overline{2} 0\rangle / / \mathrm{RD}$ orientations are more stable under RD compression. Texture analysis shows that, during RD compression, the $\langle 10 \overline{1} 0\rangle / / \mathrm{RD}$ grains rotate toward $\langle 11 \overline{2} 0\rangle / / \mathrm{RD}$. In addition, misorientation analysis shows a significant increase in GAM for the $\langle 10 \overline{1} 0\rangle / / \mathrm{RD}$ fiber. These results are consistent with those from the CPFEM simulations, which clearly show that, for compression along $\mathrm{RD}$, grains with $[11 \overline{2} 0]$ aligned with the loading direction (LD) are stable under uniaxial compression, whereas those with $[10 \overline{1} 0]$ are not. This leads to the development of a stronger $\langle 11 \overline{2} 0\rangle$ fiber after deformation, although a weaker $\langle 10 \overline{10}\rangle$ is also present. This same instability also leads to a greater degree of grain breakup in the $\langle 10 \overline{1} 0\rangle$ fiber in perturbed grain simula- tions, which is consistent with the higher GAM values obtained experimentally.

At first, this appears counter-intuitive, since both orientations have the same resolved shear stresses for prismatic slip and both orientations have a symmetric arrangement of independent slip systems, which should enable deformation in plane strain without rotation. However, the reason for their disparate behaviors becomes clear once we look closely at what happens to the Schmid factors for prismatic slip when the resolved shear stress on the highest stressed planes is not identical. This will happen in a single crystal if the grain is not perfectly oriented and in a polycrystal as a result of stresses imposed by neighboring grains, which modify the local stress state. As shown in Figure 15, unbalanced shear stresses lead to unbalanced shears and a rotation in both cases. However, the consequences of this rotation are different in each case. In the $[10 \overline{10}]$ case, this rotation increases the Schmid factor on the active slip system, leading to further rotation, whereas in the $[11 \overline{2} 0]$ case, it leads to a decrease of the Schmid factor in the active slip system and an increase in the complementary slip system, which will eventually lead to higher activity in the complementary slip system and a rotation in the opposite direction. Hence, although both orientations appear to be stable, local stress fluctuations lead to instability in the $[10 \overline{1} 0]$ case, which will rotate until it is oriented with $[11 \overline{2} 0]$ along the LD that is truly stable. This instability is similar in nature to the instability of cube grains in FCC materials. ${ }^{[36]}$

Despite their difference in orientation stabilities, the texture of the deformed material clearly shows the
Case 1 $[10 \overline{1} 0] / / L D$
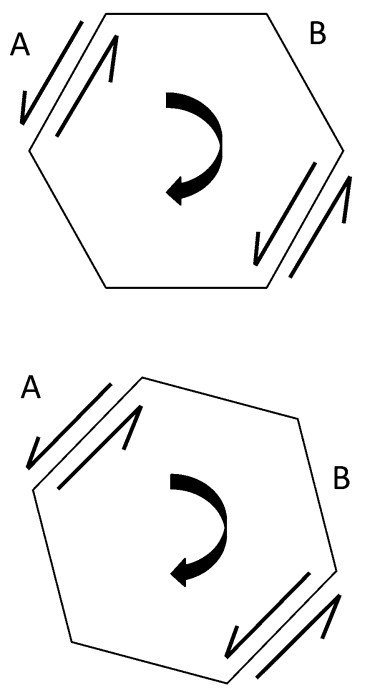

Case 2 $[11 \overline{2} 0] / / L D$
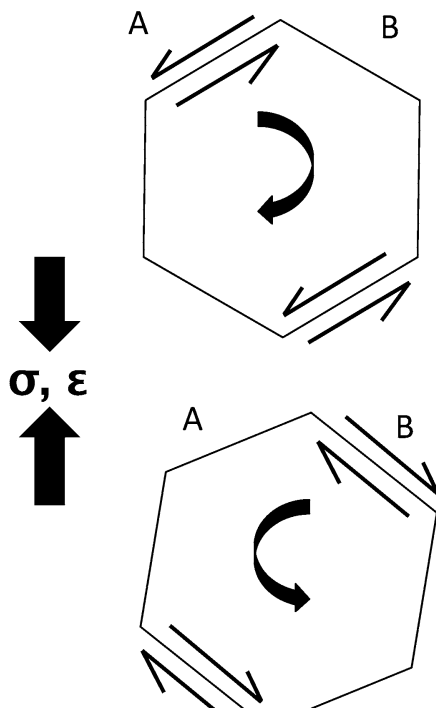

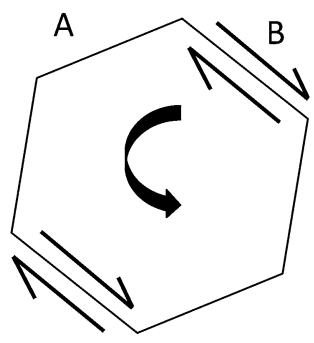

Fig. 15-Schematic explanation of the differing stabilities of the two orientations $\langle 11 \overline{2} 0\rangle / / \mathrm{LD}$ (right) and $\langle 10 \overline{1} 0\rangle / / \mathrm{LD}$ (left) under compressive deformation. $A$ and $B$ represent slip systems, and arrows represent active shearing of those slip systems. In case 1, unbalanced slip on $A$ leads to rotation away from the starting orientation, which increases the shear stress on $A$, leading to further rotation. In case 2 the same rotation leads to the activation of slip system $B$, which reverses the sense of rotation. 
development of fibers with both orientations, although the more stable one is stronger. This can be rationalized by considering the kind of intragranular stress fluctuations one expects to develop during polycrystalline deformation. Impinging neighboring grains are likely to create stress fluctuations with characteristic wavelengths shorter than the grain size, which would lead to instabilities with rotations of opposite sign. That is to say, parts of the grain will rotate clockwise to $[11 \overline{2} 0]$ along the loading direction, whereas other parts will rotate toward [1120], for example. This leads to grain breakup and instead of a complete rotation toward the stable orientation, the grain will break up into a range of orientations, which include the $[10 \overline{1} 0]$ orientation. This is illustrated by the results of the perturbed grain simulations shown in Figure 16. It can be seen that the instability discussed above gives rise to the development of strain heterogeneity and a concomitant spatial variation in rotation across the deformed grain. A compressive strain of 0.2 leads to rotations of $\pm 11 \mathrm{deg}$ about $[10 \overline{1} 0] / /$ LD (Figure 16(c)), a clear illustration of grain breakup, which looks remarkably like the grain breakup observed in the EBSD map in Figure 7(b).

Although this explanation is based on uniaxial compression, it clearly applies more generally to any nonredundant deformation. In uniaxial tension, the opposite is expected, i.e., the $\langle 10 \overline{1} 0\rangle$ fiber will be the stable orientation and in plane strain compression along

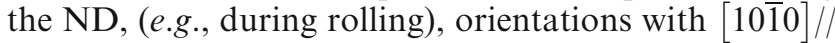
$\mathrm{RD}$ will be the most stable. This is in agreement with the stable orientation identified by Wagner et al. in titani$\mathrm{um}^{[8,37]}$ and also the observed and simulated textures in hexagonal metals where the $\{11 \overline{2} 3\}\langle 10 \overline{1} 0\rangle$ component is stronger than the $\{10 \overline{1} 3\}\langle 11 \overline{2} 0\rangle$ ) component. ${ }^{[21,38,39]}$

\section{Grain Breakup: Effect of Temperature and Loading Direction}

EBSD data analysis showed that increasing the temperature causes an increase in intergranular grain misorientation and that compression along the ND causes greater spread in orientations than the compression along the RD (Figure 9). This is slightly counterintuitive, as polycrystalline deformation usually becomes more homogenous as the temperature increases due to dynamic recovery.

CPFEM simulations were used to explore whether this behavior could be explained by the variation in the relative activities of $\langle\mathrm{c}+\mathrm{a}\rangle$ and $\langle\mathrm{a}\rangle$ slip, which is suggested by the change in deformation anisotropy. The results showed that increasing the ratio of $\langle c+a\rangle /$ $\langle a\rangle$ slip does indeed lead to an increase in the median and upper quartile of the GAM distributions for both RD compression and ND compression. Furthermore, the difference between the GAM for ND and RD also increases with both temperature (measurement (Figure 9(b))) and anisotropy (modeled (Figure 12)).

The model predicts an increase in GAM with the increasing $\langle\mathrm{c}+\mathrm{a}\rangle /\langle\mathrm{a}\rangle$ ratio, Figure 12, because the increase of plastic anisotropy increases the amount of
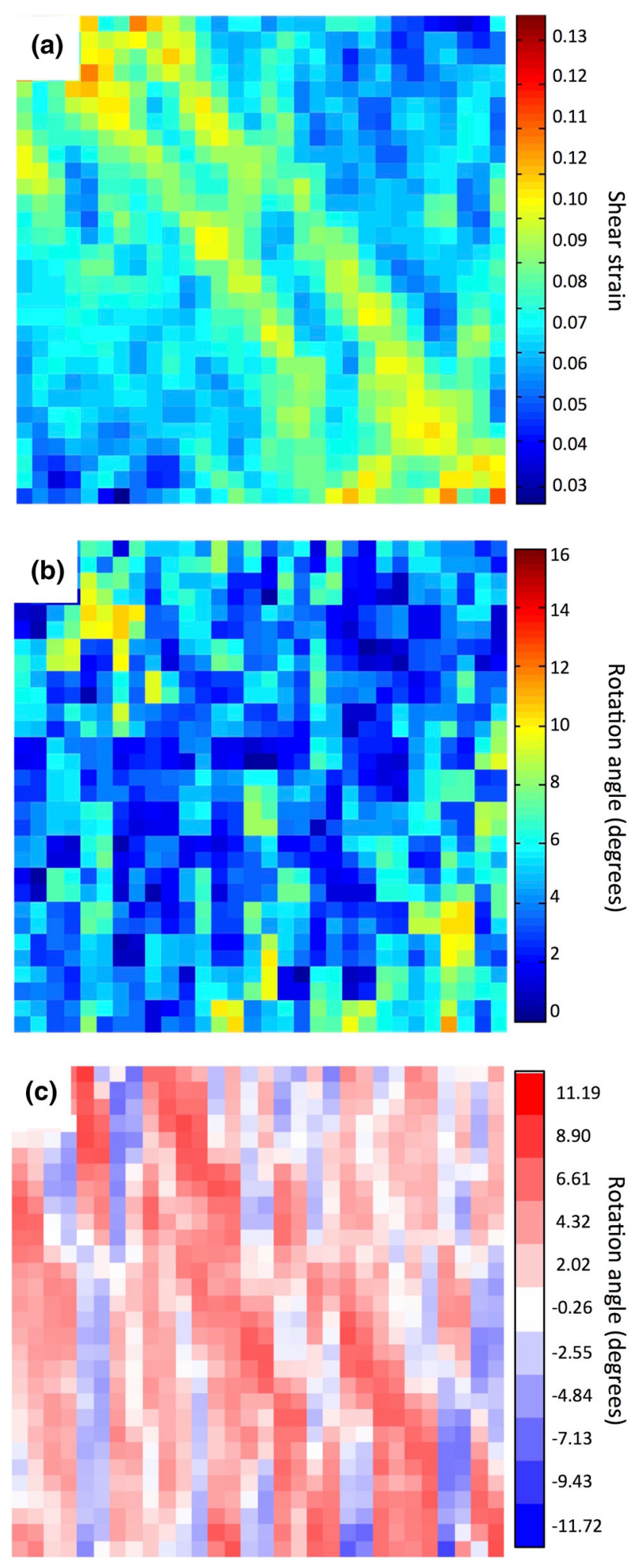

Fig. 16-A slice taken from the center of the perturbed grain aggregate compressed along the $[10 \overline{1} 0]$ axis. (a) Shear strain localizes at 45 deg to the compression axis, (b) Rotation angles from the original orientation, (c) polarized rotation angles from the original orientation. Positive rotations are shown in red and negative in blue (Color figure online). 
incompatibility between neighboring grains during deformation. This incompatibility must be accommodated by intergranular strain heterogeneity, which in turn is responsible for the development of in-grain misorientations. Therefore, the observed increase in GAM with temperature further supports the idea that $\langle c+a\rangle$ becomes relatively more difficult at higher temperatures.

As the perturbed grain simulations showed, singlegrain breakup depends strongly on the alignment of the grain with respect to principal deformation directions but our polycrystalline simulations demonstrate that this effect is not as strong in a polycrystal, and that orientation gradients develop in stable grains as well as unstable grains. This is not unexpected, as these grains will also experience incompatibilities with neighboring grains. Nevertheless, it is clear from both the experimental data and the modeling results that grains with unstable orientation develop significantly higher intragranular misorientations during polycrystalline deformation due to the grain break-up mechanism described earlier. One important point is that the predicted spreads in misorientation are narrower than those measured (Figure 12). This is, in all likelihood, due to the small number of integration points (viz. 8) used to model each grain in the polycrystal simulation, which fails to accurately represent the highly heterogeneous nature of deformation within grains. Simulations with higher numbers of integration points per orientation do indeed predict higher GAM values but were too computationally expensive to be used here.

Both the predicted and experimentally obtained GAM values for samples compressed along RD were, in all cases, lower than those for samples compressed along the ND. One potential reason is that whereas for RD compression most of the deformation occurs by prismatic slip, ND compression requires a significant contribution of $\langle c+a\rangle$ slip. However, it is not obvious why $\langle c+a\rangle$ slip should lead to higher intragranular misorientations, particularly as $\langle\mathrm{c}+\mathrm{a}\rangle$ slip appears to sharpen the texture. Another more likely reason follows from assuming that most of the intergranular orientation spread arises from prismatic slip, as described earlier and supported by the misorientation axis analysis shown in Figure 6. Since in ND compression the deformation of this material is nearly axisymmetric but grain breakup is significantly direction dependent, many more grains are likely to be unstable than in the RD compression case, resulting in a higher median GAM.

\section{Implications}

This mechanism of grain breakup via prismatic slip has important implications for the thermomechanical processing of $\mathrm{Zr}$ and other HCP materials like Ti and even $\mathrm{Mg}$, where prismatic slip dominates at large strains. It implies that, for processing in the alpha phase, homogeneous grain breakup will not be achieved unless the principal work directions are varied during processing.

Grain breakup is also important for recrystallization. The mechanism presented here predicts that the unstable components will develop heterogeneous substructures with high misorientation gradients, whereas the stable components will develop much more homogeneous substructures. Since misorientation influences the grain boundary mobility required for recrystallization, the unstable grains should have an advantage over the stable grains and should recrystallize faster, leading to a change in texture. It has long been recognized that during recrystallization, the texture of $\mathrm{Zr}$ alloys apparently "rotates" by $30 \mathrm{deg}$, and it is plausible that this texture change is a direct consequence of the different substructures developed in stable and unstable grains.

Finally, this work suggests that grain breakup will influence the development of deformation textures in $\mathrm{HCP}$ materials and that grain breakup is influenced by single crystal anisotropy through near neighbor interactions. This implies that models for texture prediction that do not consider grain interaction and cannot account for grain breakup may fail to predict these effects.

\section{CONCLUSIONS}

Mechanical testing, EBSD, and CPFEM were used to characterize the microstructural evolution during uniaxial compression of a recrystallized $\mathrm{Zr}$ alloy at different temperatures.

Analysis of the Lankford coefficient data and the misorientation axes calculated from EBSD data indicate that the anisotropy between the CRSS of $\langle c+a\rangle$ slip and $\langle a\rangle$ slip increases as the deformation temperature rises. This unexpected behavior may result from the different influences interstitial oxygen atoms have on the slip resistances of the two systems.

At $773 \mathrm{~K}\left(500{ }^{\circ} \mathrm{C}\right)$, the texture evolution during compression along RD is almost exclusively determined by prismatic slip. The $\langle 11 \overline{2} 0\rangle / / \mathrm{RD}$ fiber is stable whereas the $\langle 10 \overline{1} 0\rangle / / \mathrm{RD}$ fiber is not. A mechanism for their different stabilities has been proposed.

Grains of the stable orientation breakup less than grains with the unstable orientation. Crystal plasticity modeling of a "perturbed grain" shows that this happens through the development of intragranular deformation heterogeneity. In polycrystalline deformation, grain breakup is probably driven by intergranular stresses and deformation incompatibility of neighboring grains.

The degree of grain breakup, as measured using GAM, increases with temperature. Using CPFEM, we have shown that this is consistent with the conclusion that, for this alloy, slip anisotropy increases with temperature.

Differences in the way that grains fragment during deformation offers an explanation as to why the typical recrystallization texture change for $\mathrm{Zr}$ alloys is a rotation by $30 \mathrm{deg}$ about $\langle 0001\rangle$, from the stable texture component to the unstable texture component.

\section{ACKNOWLEDGMENTS}

The authors would like to thank the EPSRC for the partial funding of this work. Thanks are also due to Rolls-Royce plc for support by way of funding and the supply of the material. 


\section{OPEN ACCESS}

This article is distributed under the terms of the Creative Commons Attribution License which permits any use, distribution, and reproduction in any medium, provided the original author(s) and the source are credited.

\section{REFERENCES}

1. B. Cox: J. Nucl. Mater., 2005, vol. 336, pp. 331-68.

2. C.E. Coleman and D. Hardie: J. Less-Common Met., 1966, vol. 11, pp. $168-85$.

3. P. Rodriguez: Encyclopedia of Materials: Science and Technology, K.H. Jurgen-Buschow, R.W. Cahn, M.C. Flemings, B. Ilschner, E.J. Kramer, S. Mahajan, and P. Veyssière, eds., Elsevier Science Ltd, Oxford, 2001.

4. V. Fidleris: J. Nucl. Mater., 1988, vol. 159, pp. 22-42.

5. K. Vaibhaw, S.V.R. Rao, S.K. Jha, N. Saibaba, and R.N. Jayaraj: J. Nucl. Mater., 2008, vol. 383, pp. 71-77.

6. H.G. Kim, T.H. Kim, and Y.H. Jeong: J. Nucl. Mater., 2002, vol. 306, pp. 44-53.

7. G.P. Sabol: J. ASTM Int., 2005, vol. 2, pp. 3-24.

8. F. Wagner, N. Bozzolo, O. Van Landuyt, and T. Grosdidier: Acta Mater., 2002, vol. 50, pp. 1245-59.

9. S.K. Sahoo, V.D. Hiwarkar, I. Samajdar, G.K. Dey, D. Srivastav, R. Tiwari, and S. Banerjee: Scripta Mater., 2007, vol. 56, pp. 963-66.

10. K.Y. Zhu, D. Chaubet, B. Bacroix, and F. Brisset: Acta Mater., 2005, vol. 53, pp. 5131-40.

11. F. Gerspach, N. Bozzolo, and F. Wagner: Scripta Mater., 2009, vol. 60 , pp. 203-206.

12. C. Vanitha, M.K. Kumar, G.K. Dey, D. Srivastava, R. Tewari, and S. Banerjee: Mater. Sci. Eng. A Struct. Mater., 2009, vol. 519, pp. 51-60.

13. N. Dewobroto, N. Bozzolo, and F. Wagner: Icotom 14: Textures of Materials, Pts 1 and 2, 2005, vol. 495-497, pp. 711-16.

14. K.V.M. Krishna, S.K. Sahoo, I. Samajdar, S. Neogy, R. Tewari, D. Srivastava, G.K. Dey, G.H. Das, N. Saibaba, and S. Banarjee: J. Nucl. Mater., 2008, vol. 383, pp. 78-85.

15. V.D. Hiwarkar, S.K. Sahoo, I. Samajdar, A. Satpathy, K.V.M. Krishna, G.K. Dey, D. Srivastav, R. Tewari, and S. Banarjee: $J$. Nucl. Mater., 2011, vol. 412, pp. 287-93.
16. C.L. Whitmarsh: Oak Ridge National Laboratory, USA, 1962.

17. R.J. McCabe, E.K. Cerreta, A. Misra, G.C. Kaschner, and C.N. Tome: Philos. Mag., 2006, vol. 86, pp. 3595-3611.

18. G.C. Kaschner, C.N. Tome, I.J. Beyerlein, S.C. Vogel, D.W. Brown, and R.J. McCabe: Acta Mater., 2006, vol. 54, pp. 2887-96.

19. J.H. Cho, A.D. Rollett, and K.H. Oh: Metall. Mater. Trans. A, 2005, vol. 36A, pp. 3427-38.

20. Y.B. Chun, M. Battaini, C.H.J. Davies, and S.K. Hwang: Metall. Mater. Trans. A, 2010, vol. 41A, pp. 3473-87.

21. E. Tenckhoff: Deformation Mechanisms, Texture, and Anisotropy in Zirconium and Zircaloy, 1st ed., ASTM, Philadelphia, 1988.

22. P. Bate: Philos. Trans. R. Soc. A, 1999, vol. 357, pp. 1589-1601.

23. J.Q. da Fonseca and P.S. Bate: Icotom 14: Textures of Materials, Pts 1 and 2, 2005, vol. 495-497, pp. 1055-60.

24. P.S. Bate and J.Q. da Fonseca: Mater. Sci. Eng., 2004, vol. 380, pp. 365-77.

25. D.S. Sarma, K.M. Alotaibi, and K.L. Murty: Mater. Trans. JIM, 1992, vol. 33, pp. 596-603.

26. F. Xu, R.A. Holt, and M.R. Daymond: J. Nucl. Mater., 2008, vol. 373 , pp. $217-25$.

27. A. Akhtar: J. Nucl. Mater., 1973, vol. 47, pp. 79-86.

28. P. Soo and G.T. Higgins: Acta Metall., 1968, vol. 16, pp. 177-86.

29. F. Xu, R.A. Holt, and M.R. Daymond: J. Nucl. Mater., 2009, vol. 394, pp. 9-19.

30. I.J. Beyerlein and C.N. Tome: Int. J. Plast., 2008, vol. 24, pp. 86795.

31. P. Das Gupta and V.S. Arunachalam: J. Mater. Sci., 1968, vol. 3, pp. 271-81.

32. D. Caillard and J. Martin: Thermally Activated Mechanisms in Crystal Plasticity, Cambridge Univ Press, Cambridge, 2003.

33. R.J. McCabe, G. Proust, E.K. Cerreta, and A. Misra: Int. J. Plast., 2009, vol. 25, pp. 454-72.

34. G.C. Kaschner and G.T. Gray: Metall. Mater. Trans. A, 2000, vol. 31A, pp. 1997-2003.

35. A.T. Churchman: Proc. R. Soc. Lond. Ser. A, 1954, vol. 226, pp. $216-26$

36. D. Raabe, Z. Zhao, and F. Roters: Scripta Mater., 2004, vol. 50, pp. $1085-90$

37. O. Van Landuyt, T. Grosdidier, and F. Wagner: Icotom 12, J.A. Szpunar, eds., NRC Research Press, Montreal Canada, 1999.

38. T. Mayama, M. Noda, R. Chiba, and M. Kuroda: Int. J. Plast., 2011, vol. 27, pp. 1916-35.

39. M.J. Philippe, M. Serghat, P. Vanhoutte, and C. Esling: Acta Metall. Mater., 1995, vol. 43, pp. 1619-30. 